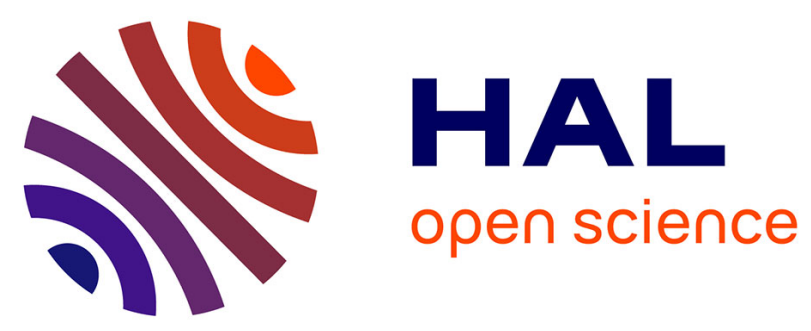

\title{
A Water-Compatible NHC-Borane: Photopolymerizations in Water and Rate Constants for Elementary Radical Reactions
}

Mohamad-Ali Tehfe, Julien Monot, Max Malacria, Louis Fensterbank, Jean-Pierre Fouassier, Dennis P. Curran, Emmanuel Lacôte, Jacques Lalevée

\section{To cite this version:}

Mohamad-Ali Tehfe, Julien Monot, Max Malacria, Louis Fensterbank, Jean-Pierre Fouassier, et al.. A Water-Compatible NHC-Borane: Photopolymerizations in Water and Rate Constants for Elementary Radical Reactions. ACS Macro Letters, 2012, 1 (1), pp.92-95. 10.1021/mz200087g • hal-01397626

\section{HAL Id: hal-01397626 \\ https://hal.science/hal-01397626}

Submitted on 5 May 2020

HAL is a multi-disciplinary open access archive for the deposit and dissemination of scientific research documents, whether they are published or not. The documents may come from teaching and research institutions in France or abroad, or from public or private research centers.
L'archive ouverte pluridisciplinaire HAL, est destinée au dépôt et à la diffusion de documents scientifiques de niveau recherche, publiés ou non, émanant des établissements d'enseignement et de recherche français ou étrangers, des laboratoires publics ou privés. 


\title{
A Water-Compatible NHC-Borane: Photopolymerizations in Water and Rate Constants for Elementary Radical Reactions
}

\author{
Mohamad-Ali Tehfe, ${ }^{\dagger}$ Julien Monot, ${ }^{\ddagger}$, Max Malacria, $^{\ddagger}$ Louis Fensterbank, ${ }^{\ddagger}$ Jean-Pierre Fouassier, $"$ \\ Dennis P. Curran, ${ }^{\S}$ Emmanuel Lacôte, ${ }^{*, \perp}$ and Jacques Lalevée ${ }^{* \dagger} \dagger$ \\ ${ }^{\dagger}$ Institut de Science des Matériaux de Mulhouse IS2M, LRC CNRS 7228, ENSCMu-UHA; 15, rue Jean Starcky, 68057 Mulhouse \\ Cedex, France \\ ${ }^{\ddagger}$ UPMC Univ Paris 06, Institut Parisien de Chimie Moléculaire (UMR CNRS 7201), C. 229, 4 place Jussieu, 75005 Paris, France \\ ${ }^{\S}$ Department of Chemistry, University of Pittsburgh, Pittsburgh, Pennsylvania 15260, United States \\ ${ }^{\perp}$ Institut de Chimie des Substances Naturelles CNRS, Av. de la Terrasse, 91198 Gif-sur-Yvette Cedex, France \\ "Université de Haute Alsace, 68200 Mulhouse, France
}

\section{Supporting Information}

\begin{abstract}
Rate constants for important elementary reactions of 2,4-dimethyl-1,2,4-triazol3 -ylidene borane $(\mathbf{1})$ and its derived boryl radical have been measured in the presence and absence of water. Reactions including $\mathrm{H}$-abstraction by $t \mathrm{BuO}^{\circ}$, and onward reactions of the derived radical with methyl acrylate (addition), iodopropane (halogen abstraction), and an iodonium salt (oxidation) are unaffected by the presence of a high concentration $(1.5 \mathrm{M})$ of water. Extending these results, borane (1) has been found to be an efficient new co-initiator for the visible light photopolymerization of monomers in the presence of both air and water.
\end{abstract}

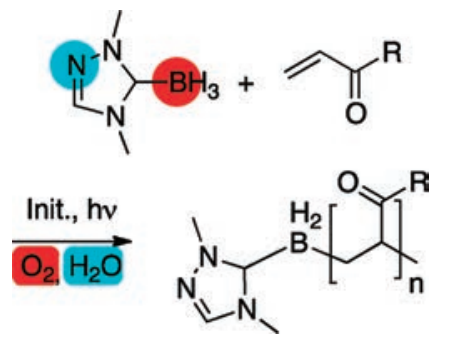

$\mathrm{N}$ -Heterocyclic carbene-borane complexes (NHC-boranes $)^{1}$ are rapidly emerging as useful reagents in organic synthesis ${ }^{2}$ and as convenient co-initiators in radical polymerizations. ${ }^{3}$ These uses are enabled by the strong association between the N-heterocyclic carbene and the borane.

NHC-boranes, such as 2 (2,4-dimethyl-2,4-imidazolylidene borane, Figure 1), are excellent co-initiators for radical

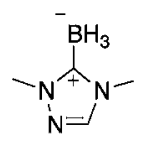

1

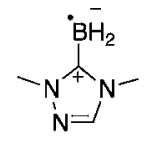

1 .

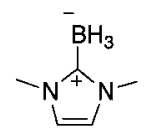

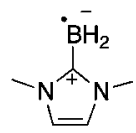

2.
Figure 1. NHC-boranes used for this study and the corresponding boryl radicals. Formal charges of the Lewis pair are shown. For clarity, they are omitted in the rest of the manuscript.

photopolymerizations in the presence of air but in the absence of water. ${ }^{3}$ Recently, we introduced NHC-borane 1 (2,4dimethyl-1,2,4-triazol-3-ylidene borane, Figure 1) as a reagent for radical reduction of halides bearing nearby electron withdrawing groups. ${ }^{4}$ Interestingly, $\mathbf{1}$ is stable to water and also exhibits good solubility in water. A convenient aqueous extraction procedure served to separate unreacted $\mathbf{1}$ and its derived products from reactant-derived products after the radical reactions. ${ }^{4 \mathrm{~b}}$ We wondered whether 1 could be used as a co-initiator for photopolymerization in the presence of both air and water. For that purpose, initiators must be both highly efficient and soluble to ensure good polymer growth, which limits their availability. ${ }^{5}$
Water and other protic solvents have a significant impact on some types of radical reactions. ${ }^{6}$ Carbene boranes also react as hydrides. $^{2 \mathrm{~b}, \mathrm{c}}$ Thus water might $\mathrm{H}$-bond to both the mediator and the intermediate boryl radicals. The efficiency of the initiation might then be affected, because it derives from cleavage of the $\mathrm{B}-\mathrm{H}$ bond under photochemical conditions.

To understand how 1 might behave in photopolymerizations under wet conditions, we have determined the rate constants for representative reactions of $\mathbf{1}$ and its derived radical in acetonitrile in both the absence and the presence of water with the help of laser flash photolysis (LFP). These data were augmented by DFT calculations. The resulting suggestion that 1 should behave as a photopolymerization co-initiator in the presence of both air and water was then verified by a series of model polymerization experiments.

The NHC-boryl radical $\mathbf{1}^{\bullet}$ was formed by LFP through the quenching of the tert-butoxyl radical $t$ - $\mathrm{BuO}^{\bullet}$ (eq 1 ). $t$ - $\mathrm{BuO}^{\bullet}$ was chosen because it is easily obtained by the direct cleavage of ditert-butylperoxide at $355 \mathrm{~nm}^{7}$ and cannot be observed in this spectral range. The transient absorption spectra for $\mathbf{1}^{\bullet}$ exhibit a broad absorption for $\lambda<400 \mathrm{~nm}$ (Figure S1), which was also the case for $2^{\bullet}{ }^{3 \mathrm{~b}}$ The LFP experiments were carried out under argon because the NHC-boryl radicals react rapidly with oxygen (see below).

The formation and structure of the NHC-boryl radical $\mathbf{1}^{\bullet}$ were also assessed by ESR-spin trapping experiments (Figure 
$1 \mathrm{~B}$ in SI). The nitroxide spin adduct obtained from the addition of $\mathbf{1}^{\circ}$, generated by irradiating a $0.06 \mathrm{M}$ solution of $\mathbf{1} \mathrm{in} \mathrm{MeCN} /$ $t \mathrm{BuOO} t \mathrm{Bu}$, onto phenyl- $N$ - $t$-butylnitrone $(\mathrm{PBN}, 0.05 \mathrm{M})$ is characterized by $a_{\mathrm{N}}=15.4 \mathrm{G}, a_{\mathrm{H}}=2.65 \mathrm{G}$, and $a_{\mathrm{B}}=4.1 \mathrm{G}$, which correlates well with previous data on boryl radicals. ${ }^{3} \mathrm{~A}$ nitroxide spin adduct of $\mathbf{1}^{\bullet}$ and PBN with similar hyperfine coupling constants was detected in the presence of water $\left(\left[\mathrm{H}_{2} \mathrm{O}\right]=0.9 \mathrm{M}\right)$.

$$
\begin{aligned}
& t-\mathrm{BuO}^{\bullet}+\mathrm{NHC}-\mathrm{BH}_{3} \\
& \quad \rightarrow t-\mathrm{BuOH}+\mathrm{NHC}-\mathrm{BH}_{2} \bullet\left(k_{\mathrm{H}}\right)
\end{aligned}
$$

A solution of $t \mathrm{BuOO} t \mathrm{Bu}$ and $\mathbf{1}$ in acetonitrile was irradiated by LFP, and the rate of formation of $\mathbf{1}^{\bullet}$ was measured by following the rising time $(\tau)$ of its $\mathrm{UV}$ absorption at $\lambda=360 \mathrm{~nm}$ (Figure 2A). This provides direct access to the hydrogen
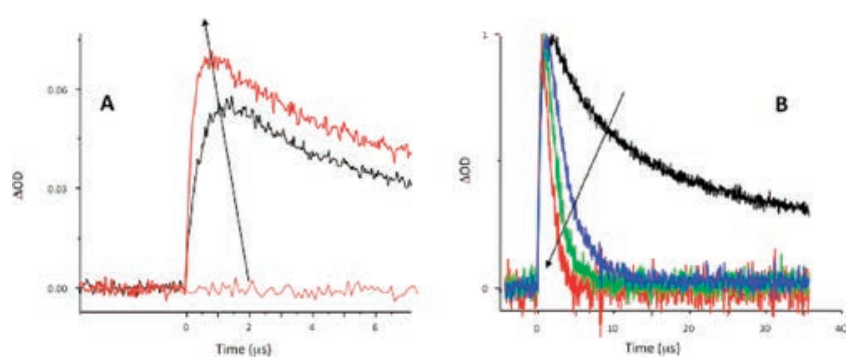

Figure 2. (A) LFP rate constant determination of the formation of radicals from 1 at $\lambda=360 \mathrm{~nm}$ (acetonitrile/di-tert-butylperoxide); (B) Kinetics at $360 \mathrm{~nm}$ corresponding to the decay of $\mathbf{1}^{\bullet}$ for different $\left[\mathrm{C}_{3} \mathrm{H}_{7} \mathrm{I}\right]$ (from 0 to $0.03 \mathrm{M}$ ).

abstraction rate constant $k_{\mathrm{H}}$ through a Stern-Volmer plot of 1/ $\tau$ against the quencher concentration (Figure S2). ${ }^{7}$

The values of $k_{\mathrm{H}}$ for formation of $\mathbf{1}^{\bullet}$ and other rate contants for its onward reactions in both dry and wet acetonitrile are shown in Table 1 . The concentration of water was limited to

Table 1. Measured Rate Constants for Several Radical

\begin{tabular}{|c|c|c|c|}
\hline $\begin{array}{l}\text { NHC } \\
\text { borane }\end{array}$ & $\begin{array}{c}k_{\mathrm{H}}^{1}{ }^{a}\left(t \mathrm{Bu}-\mathrm{O}^{\bullet}\right) \\
\mathrm{M}^{-1} \mathrm{~s}^{-1}\end{array}$ & $\begin{array}{c}k_{\text {add }}\left(\mathrm{R}^{\bullet} / \mathrm{MA}\right) \times \\
10^{6} \mathrm{M}^{-1} \mathrm{~s}^{-1}\end{array}$ & $\begin{array}{l}k_{\text {add }}^{\prime}\left(\mathrm{R}^{\bullet} / \mathrm{O}_{2}\right) \times \\
10^{8} \mathrm{M}^{-1} \mathrm{~s}^{-1}\end{array}$ \\
\hline 1 & 14 & 17 & $>6$ \\
\hline 2 & 26 & 38 & $>6$ \\
\hline \multirow{2}{*}{$\begin{array}{l}1+ \\
\text { water }^{b}\end{array}$} & 15 & 25 & $>6$ \\
\hline & \multicolumn{3}{|c|}{$k_{\text {ox }}\left(\mathrm{R}^{\bullet} / \mathrm{Ph}_{2} \mathrm{I}^{+}\right) \times 10^{9} \mathrm{M}^{-1} \mathrm{~s}^{-1} \quad k_{\mathrm{I}}\left(\mathrm{R}^{\bullet} / \mathrm{C}_{3} \mathrm{H}_{7} \mathrm{I}\right) \times 10^{7} \mathrm{M}^{-1} \mathrm{~s}^{-1}$} \\
\hline 1 & \multicolumn{2}{|l|}{1.5} & 3.2 \\
\hline 2 & \multicolumn{2}{|l|}{0.8} & 18 \\
\hline $1+$ water $^{b}$ & \multicolumn{2}{|l|}{1.4} & 4.2 \\
\hline
\end{tabular}
Elementary Steps in Formation and Onward Reactions of $\mathbf{1}^{\bullet}$

1.5 $\mathrm{M}$ in acetonitrile/di-tert-butylperoxide to ensure that the medium was homogeneous. Higher concentrations of water lead to demixing. Previously measured rate constants for $\mathbf{2}$ in dry acetonitrile are included in Table 1 for comparison.

The $t \mathrm{BuO}^{\bullet}$ radical abstracts hydrogen very rapidly from $\mathbf{1}$ in both the presence and absence of water. The measured rate constants $\left(k_{\mathrm{H}} \approx 1.5 \times 10^{8} \mathrm{M}^{-1} \mathrm{~s}^{-1}\right)$ are within experimental error, indicating that water does not influence the hydrogen abstraction process. Triazole borane $\mathbf{1}$ is also comparable in reactivity to imidazole borane 2 .
To better understand the similaries, we calculated the $\mathrm{B}-\mathrm{H}$ bond dissociation energy (BDE) of $\mathbf{1}$ and the structure of $\mathbf{1}^{\bullet}$ at the UB3LYP/6-31+G* level (see Supporting Information) for comparison to analogous published data of $2 .{ }^{8}$ The calculated $\mathrm{B}-\mathrm{H}$ BDEs of $\mathbf{1}$ and 2 ( 80.4 and $81.9 \mathrm{kcal} \mathrm{mol}^{-1}$ ) are similar, as are the spin densities on boron in $1^{\circ}$ and $2^{\circ}(0.53$ and 0.55$)$ and on the two common nitrogen atoms. The "extra" nitrogen in $1^{\bullet}(\mathrm{N} 2)$ has a very low calculated spin density (0.04). Diagrams of the SOMOs for $\mathbf{1}^{\bullet}$ and $\mathbf{2}^{\bullet}$ (Figure S3) also show the small participation of $\mathrm{N} 2$ in the spin distribution.

The rate constants for radical-molecule reactions were measured through the direct observation of the decay $\mathbf{1}^{\bullet}$ following LFP. Solutions of $t \mathrm{BuOO} t \mathrm{Bu}$ and $\mathbf{1}$ in acetonitrile were irradiated by LFP in the presence of varying concentrations of reactants, with and without $1.5 \mathrm{M}$ water. The rate of decay of $\mathbf{1}^{\bullet}$ was measured by following the decrease of its UV absorption at $\lambda=360 \mathrm{~nm}$ (Figure 2B), and this data was processed in the usual way to give the elementary rate constants shown in Table 1.

Elementary processes relevant to NHC-borane organic radical reactions and polymer synthesis were considered. These are (1) addition of $\mathbf{1}^{\bullet}$ to a representative monomer (methyl acrylate, MA, Figures S4A and S6); (2) reaction of $\mathbf{1}^{\circ}$ with dioxygen (Figure S5); (3) oxidation of $\mathbf{1}^{\bullet}$ to the corresponding borenium ion by diphenyl iodonium hexafluorophosphate $\left(\mathrm{Ph}_{2} \mathrm{IPF}_{6} ;\right.$ Table 1, Figure S4B and S7); and (4) halogen abstraction from iodopropane by $\mathbf{1}^{\bullet}$ (Figures $2 \mathrm{~B}$ and S8).

All four reactions of $\mathbf{1}^{\bullet}$ are rapid, with MA addition and iodine abstraction in the range of $10^{7} \mathrm{M}^{-1} \mathrm{~s}^{-1}$ and the two oxidations in the range of $10^{9} \mathrm{M}^{-1} \mathrm{~s}^{-1}$. The rate constants for the four reactions of $1^{\bullet}$ and $2^{\bullet}$ do not vary much (less than 1 order of magnitude for all of them). Importantly, the rate constants for radical-molecule reactions of $\mathbf{1}^{\bullet}$ were not affected by the presence of water, despite the polar nature of some of the reactant pairs and possible H-bonding.

The transition state for the addition of $1^{\bullet}$ onto MA was calculated at the UB3LYP/6-31+G* level (Figure S9; the TS geometry was frequency checked). There was a high charge transfer from $1^{\bullet}$ to $\mathrm{MA}$ in the TS $\left(+0.14 \mathrm{e}^{-}\right)$. This indicates that $\mathbf{1}^{\bullet}$ is nucleophilic, which agrees well with its rapid oxidation by $\mathrm{Ph}_{2} \mathrm{I}^{+}$and its low calculated ionization potential (5.88 eV at UB3LYP/6-31+G* level). A similar behavior was found for other boryl radicals. ${ }^{3}$

Polymerization in the presence of water has considerable practical importance. The high reactivity of $\mathbf{1}$ and $\mathbf{1}^{\circ}$, as well as their tolerance to water led us to evaluate $\mathbf{1}$ as a co-initiator in the photopolymerization of 2-hydroxyethyl acrylate $\left(\mathrm{CH}_{2}=\right.$ $\left.\mathrm{CH}-\mathrm{C}(=\mathrm{O}) \mathrm{OCH}_{2} \mathrm{CH}_{2} \mathrm{OH}, \mathrm{HEA}\right)$ to poly-2-hydroxyethyl acrylate (PHEA) in the presence of different photoinitiators.

A 50/50 (w/w) solution of HEA and water containing 1 (3\% $\mathrm{w} / \mathrm{w})$ and different water-soluble initiators $(0.1 \mathrm{~mol} \%)$ was irradiated with a $\mathrm{Xe}-\mathrm{Hg}$ lamp for $13 \mathrm{~min}$, then the resulting sample of PHEA was characterized by size exclusion chromatography (SEC, Figure 3). The number average molecular weight $\left(M_{\mathrm{n}}\right)$ of the sample was $3300 \mathrm{~g} \cdot \mathrm{mol}^{-1}$ with a polydispersity index (PDI) of 3.3. Photopolymerization of HEA was not observed with the photoinitiator (1-chloro-4hydroxy thioxanthone or benzophenone) or $\mathbf{1}$ alone. This shows that the two-component system is required for efficient initiation.

Photopolymerizations of a bulk acrylate monomer (trimethylolpropane triacrylate TMPTA) using benzophenone (BP), 


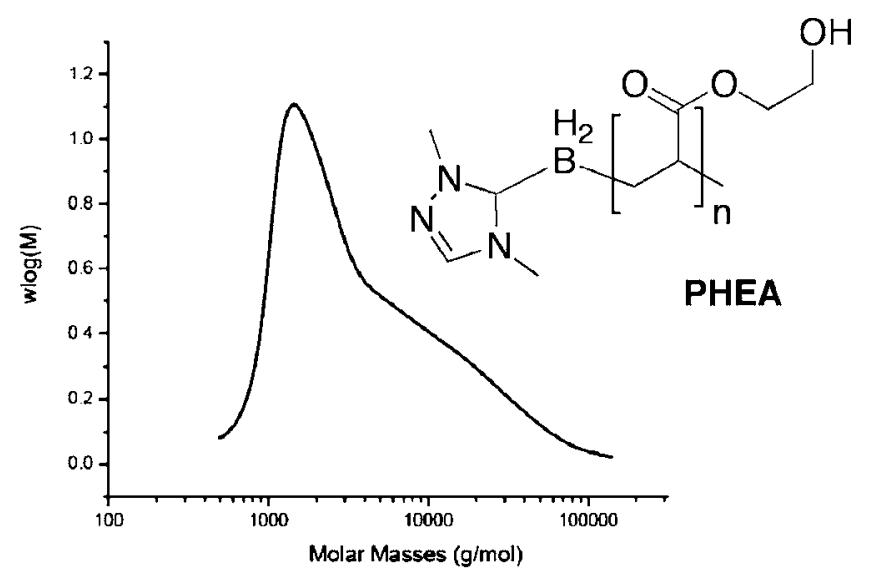

Figure 3. SEC analysis of the PHEA synthetized with the new initiating system (detection of the polymer chains by refractive index detection); Initiating system: $1(3 \% \mathrm{w} / \mathrm{w})$ and water-soluble initiator (0.1\%; see SI for experimental detail).

camphorquinone (CQ), 2-isopropyl-thioxanthone (ITX), and Eosin- $\mathrm{Y}$ as photoinitiators in both the absence and presence of 1 were carried out next (Figure 4). Photopolymerizations were carried out in laminated conditions (Figure 4A) or in bulk under air (Figure 4B).
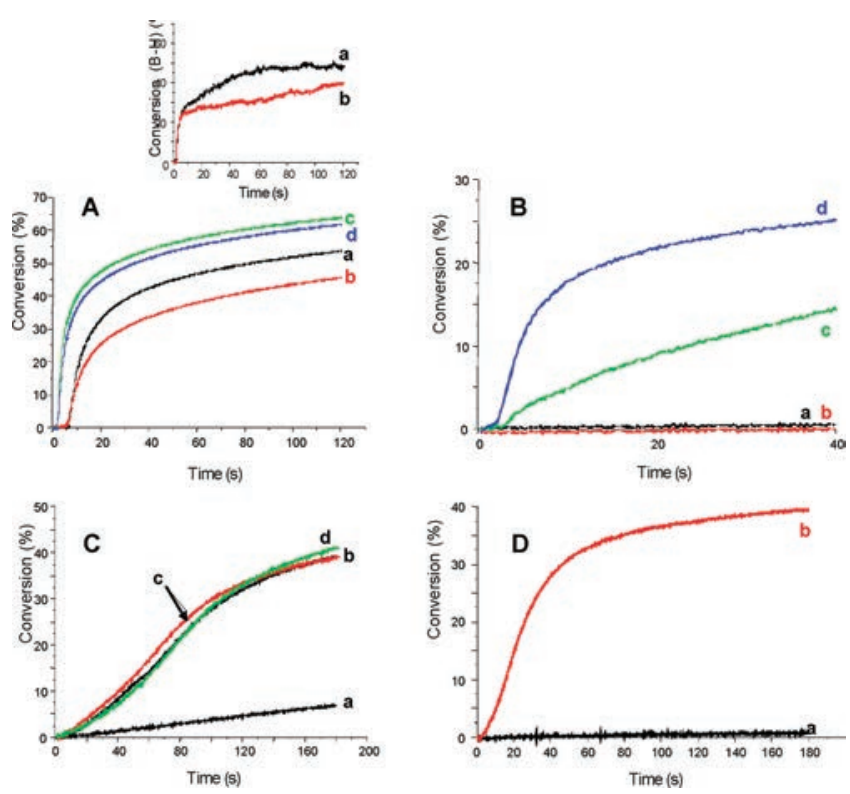

Figure 4. Polymerization profiles of TMPTA for different photoinitiating systems: (A) BP (1\% w/w; a); 1 (1\% w/w; b); BP/EDB (1/ $1 \% \mathrm{w} / \mathrm{w} ; \mathrm{c}) ; \mathrm{BP} / 1(1 / 1 \% \mathrm{w} / \mathrm{w} ; \mathrm{d})$; in laminate; Xe-Hg lamp. (B) BP $(1 \% \mathrm{w} / \mathrm{w} ; \mathrm{a}) ; 1$ ( $1 \% \mathrm{w} / \mathrm{w} ; \mathrm{b}) ; \mathrm{BP} / \mathrm{EDB}(1 / 1 \% \mathrm{w} / \mathrm{w} ; \mathrm{c}) ; \mathrm{BP} / 1(1 / 1 \%$ w/w; d); under air; Xe-Hg lamp. (C) CQ (3\% w/w; a); CQ/1 (3/3\% $\mathrm{w} / \mathrm{w} ; \mathrm{b}) ; \mathrm{CQ} / \mathbf{1}(3 / 3 \% \mathrm{w} / \mathrm{w})$ - water $5 \% \mathrm{w} / \mathrm{w}(\mathrm{c}) ; \mathrm{CQ} / \mathbf{1}(3 / 3 \% \mathrm{w} / \mathrm{w})$ - water $10 \% \mathrm{w} / \mathrm{w}(\mathrm{d})$; under air; diode laser $473 \mathrm{~nm}$. (D) ITX (1\% w/ w; a); ITX/1 (1/1\% w/w; b); under air; Xenon lamp, $\lambda>400 \mathrm{~nm}$. Inset: conversion of $\mathrm{B}-\mathrm{H}\left(2200-2475 \mathrm{~cm}^{-1}\right)$ associated with the polymerization profiles of TMPTA for different photoinitiating systems: $\mathrm{BP} / 1(1 / 1 \% \mathrm{w} / \mathrm{w} ;$ a) under air; $\mathrm{BP} / \mathbf{1}(1 / 1 \% \mathrm{w} / \mathrm{w} ; \mathrm{b})$ in laminate; $\mathrm{Xe}-\mathrm{Hg}$ lamp.

In laminate (Figure 4A), the photopolymerizations using benzophenone (curve a) or $\mathbf{1}$ (curve b) still exhibited high inhibition periods and were inefficient. On the contrary, for $\mathrm{BP} / 1$ (curve $\mathrm{d}$ ), the photopolymerization process started immediately upon irradiation and the polymerization profile was similar to that obtained for the standard BP/ethyldimethylaminobenzoate (EDB) initiating system $^{5}$ (curve c). That $\mathbf{1}$ is an excellent co-initiator correlates well with the previous observations, including the high rate constant for the hydrogen abstraction reaction of 1 with $t \mathrm{BuO}^{\bullet}$, the high rate constant of addition $\mathbf{1}^{\bullet}$ onto acrylate (see Table 1 ), and the irreversibility of this addition.

Gratifyingly, replacing the standard EDB in the initiation system with 1 led to higher and more rapid monomer conversion in the presence of air (Figure 4B, compare curves $c$ and $\mathrm{d}$ ). We believe that, contrary to EDB, 1 overcomes the oxygen inhibition of free radical polymerization because it can regenerate the active initiating species $\mathbf{1}^{\bullet}$ from the peroxyl radicals produced under air from both initiating and propagating radicals. ${ }^{3 \mathrm{~b}}$

The number of $\mathrm{B}-\mathrm{H}$ bonds present in the system decreases during the polymerization process, and this was followed by FTIR spectroscopy by monitoring the decrease in the $\mathrm{B}-\mathrm{H}$ stretching band at $2200-2475 \mathrm{~cm}^{-1}$ in the polymerization initiated by the BP/1 photoinitiating system $(1 / 1 \% \mathrm{w} / \mathrm{w})$. The $\mathrm{B}-\mathrm{H}$ conversion was higher in bulk under air than in laminated conditions, in agreement with the previous observation (Figure $4 \mathrm{~A}$, inset).

NHC-borane 1 can be used as co-initiator for photopolymerization with other photoinitiators including CQ (Figure 4C, laser diode $473 \mathrm{~nm}$ ) and ITX (Figure 4D, Xenon lamp). Unlike the BP/1 system, which requires UV irradiation, Eosin$\mathrm{Y} / \mathbf{1}$ is a visible-light photoinitiating system $(\lambda=532 \mathrm{~nm})$. This is especially important for applications requiring visible light irradiations.

Last, irradiation of the monomer using the CQ/ 1 initiating system in the presence of $5 \% \mathrm{w} / \mathrm{w}$ (Figure $4 \mathrm{C}$, curve c) or $10 \%$ $\mathrm{w} / \mathrm{w}$ water (Figure 4C, curve $\mathrm{d}$ ) did not change the polymerization profile (compare to Figure $4 \mathrm{C}$, curve $\mathrm{b}$ ). Thus, $\mathbf{1}$ is also a good co-initiator for polymerization of more lipophilic monomers in the presence of water.

To conclude, NHC-borane $\mathbf{1}$ is an excellent co-initiator for free radical polymerization, which proceeds under light activation (UV or visible) in the presence of air and water. This expands the scope of monomers polymerizable with NHC-borane co-initiators and opens important perspectives for green polymer and organic chemistries.

\section{ASSOCIATED CONTENT}

\section{Supporting Information}

UV and LFP spectra and Stern-Volmer treatments, as well as modeling results. This material is available free of charge via the Internet at http://pubs.acs.org.

\section{AUTHOR INFORMATION}

\section{Corresponding Author}

*E-mail: emmanuel.lacote@icsn.cnrs-gif.fr; j.lalevee@uha.fr.

\section{Notes}

The authors declare no competing financial interest.

\section{ACKNOWLEDGMENTS}

We thank UHA, CNRS, UPMC, and the U.S. National Science Foundation (CHE-0645998) for funding. Dr. Didier Gigmes and Marion Rollet (Laboratoire de Chimie de Provence, Marseille) are acknowledged for help with the SEC analysis. 


\section{REFERENCES}

(1) Curran, D. P.; Solovyev, A.; Makhlouf Brahmi, M.; Fensterbank, L.; Malacria, M.; Lacôte, E. Angew. Chem., Int. Ed. 2011, 50, 1029410317.

(2) (a) Ueng, S.-H.; Makhlouf Brahmi, M.; Derat, É.; Fensterbank, L.; Lacôte, E.; Malacria, M; Curran, D. P. J. Am. Chem. Soc. 2008, 130, 10082-10083. (b) Chu, Q.; Makhlouf Brahmi, M.; Solovyev, A.; Ueng, S.-H.; Curran, D. P.; Malacria, M.; Fensterbank, L.; Lacôte, E. Chem.-Eur. J. 2009, 15, 12937-12940. (c) Lindsay, D. M.; McArthur, D. Chem. Commun. 2010, 46, 2474-2476.

(3) (a) Thefe, M.-A.; Makhlouf Brahmi, M.; Fouassier, J.-P.; Curran, D. P.; Malacria, M.; Fensterbank, L.; Lacôte, E.; Lalevée, J. Macromolecules 2010, 43, 2261-2267. (b) Tehfe, M.-A.; Monot, J.; Makhlouf Brahmi, M.; Bonin-Dubarle, H.; Curran, D. P.; Malacria, M.; Fensterbank, L.; Lacôte, E.; Lalevée, J.; Fouassier, J.-P. Polym. Chem. 2011, 2, 625-631.

(4) (a) Ueng, S.-H.; Fensterbank, L.; Lacôte, E.; Malacria, M.; Curran, D. P. Org. Lett. 2010, 12, 3002-3005. (b) Ueng, S.-H.; Fensterbank, L.; Lacôte, E.; Malacria, M.; Curran, D. P. Org. Biomol. Chem. 2011, 3415-3420.

(5) (a) Fouassier, J.-P. In Photoinitiation, Photopolymerization and Photocuring: Fundamental and Applications; Hanser Publishers: New York, 1995; (b) Photoinitiated Polymerization; Belfied, K. D., Crivello, J. V., Eds.; ACS Symposium Series 847; American Chemical Society: Washington, DC, 2003.

(6) (a) Litwinienko, G.; Beckwith, A. L. J.; Ingold, K. U. Chem. Soc. Rev. 2011, 40, 2157-2163. (b) Lalevée, J.; Fouassier, J.-P.; Blanchard, N.; Ingold, K. U. Chem. Phys. Lett. 2011, 511, 156-158.

(7) (a) Lalevée, J.; Allonas, X.; Fouassier, J.-P. J. Am. Chem. Soc. 2002, 124, 9613-9621. (b) Lalevée, J.; Graff, B.; Allonas, X.; Fouassier, J.-P. J. Phys. Chem. A 2007, 111, 6991-6998.

(8) (a) Ueng, S.-H.; Solovyev, A.; Yuan, X.; Geib, S. J.; Fensterbank, L.; Lacôte, E.; Malacria, M.; Newcomb, M.; Walton, J. C.; Curran, D. P. J. Am. Chem. Soc. 2009, 131, 11256-11262. (b) Hioe, J.; Karton, A.; Martin, J. M. L.; Zipse, H. Chem.-Eur. J. 2010, 23, 6861-6865. 